\section{EL DEBATE SOBRE LA INMIGRACIÓN COMO DISCURSO ONTOLÓGICO-POLÍTICO}

\author{
Alessandro Pinzani* \\ Profesor de filosofía política en la UFSC \\ (Florianópolis, Brasil) \\ migrante
}

\section{THE DEBATE ON IMMIGRATION AS ONTOLOGICAL-POLITICAL DISCOURSE}

\begin{abstract}
This essay debates some thesis on immigration generally and on clandestine immigration particularly: 1) the best way to discuss the question of immigration is by using Foucault's concept of device, which allows to consider the debate on this question as being a part of the mechanism of control on immigration itself. 2) There is a first difficulty in defining the concept of immigrant. 3) In the debate on immigration one can distinguish two official discourses, i.e., the control discourse and the adaptation discourse, which hide an attitude of rejection of the Other. 4) The debate establishes an ontological distinction between immigrants and citizens in the sense of a political ontology that aims at defining political community through the opposition to the Other.
\end{abstract}

KEY WORDS: Immigration; migration politics; device; political ontology; collective identity.

\begin{abstract}
RESUMEN: Este artículo discute algunas tesis acerca de la inmigración en general y de la inmigración clandestina en particular. Éstos son los pasos: 1) La manera mejor para discutir sobre la cuestión de la inmigración es servirse del concepto foucaltiano de dispositivo, que permite considerar el debate sobre tal cuestión como parte del mecanismo de control de la propia inmigración. 2) Hay una primera dificultad en la definición de la propia figura del inmigrante. 3) En el debate acerca de la inmigración se pueden distinguir dos discursos oficiales: el discurso del control y el discurso de la adaptación, que todavia esconden una posición de rechazo del Otro. 4) El debate establece una distinción ontológica entre los inmigrantes y los ciudadanos, en el sentido de una ontología política que busca definir la comunidad política a través de la contraposición al Otro.
\end{abstract}

PALABRAS CLAVE: Inmigración; política migratoria; dispositivo; ontologia política; identidad colectiva.

Si es verdad que un ser humano es (o puede tornarse en) persona solamente como ciudadano, el debate filosófico sobre el Otro o sobre el extranjero deja de ser un mero ejercicio verbal únicamente si se impone el problema de la condición jurídico-política a partir de la cual un otro se coloca en relación a su semejante.

(Alessandro Dal Lago, 2008, 220)

Este artículo parte de algunas tesis acerca de la inmigración en general y de la inmigración clandestina en particular. Naturalmente, no es mi intención discutirlas todas exhaustivamente, pues para esto sería necesario un libro completo. Las tesis son las siguientes:

1) La mejor manera de discutir sobre la cuestión de la inmigración tal vez sea servirse del concepto foucaltiano de dispositivo, pues nos permite considerar el debate sobre la cuestión como parte del mecanismo de control (o de presunto control) de la propia inmigración. Desde este punto de vista, el debate sobre la inmigración es un debate político y no científico ${ }^{1}$, aunque a veces adopte un tono aparentemente neutro. Esto significa que los datos empíricos sobre la inmigración (sobre el número efectivo de inmigrantes en una cierta sociedad, sobre su papel en la economía nacional, etc.) son, en realidad, menos importantes que otras consideraciones estrictamente políticas. Tal debate político se funda más sobre las emociones que sobre el raciocinio ${ }^{2}$ y produce dos opuestas ideologizaciones $^{3}$ : por un lado, la condena, por parte de los defensores de la identidad nacional, del cosmopolitismo vacuo de los que tienen una visión positiva de la inmigración; y, por otro, la acusación de xenofobia y de eurocentrismo contra aquéllos por parte de los "cosmopolitas" y de los relativistas culturales, respectivamente. 
2) La primera dificultad consiste en la definición de la propia figura del inmigrante. El fenómeno de la inmigración da lugar a una posición contradictoria tanto en la teoría como en la práctica. Por un lado, el inmigrante es visto como una amenaza a la integridad de nuestra sociedad y como un peligroso competidor para los "nativos" en el mercado de trabajo; por otro lado, es considerado como un ser necesitado e incapaz de garantizarse la vida sin explotar nuestro sistema de bienestar social. Además, el debate se sirve de generalizaciones, en particular de la generalización que hace de los inmigrantes "los inmigrantes". De esta manera, ellos pierden su individualidad (su nombre y su biografía particulares) y se tornan meros miembros de un grupo, de una totalidad que, a su vez, es definida negativamente (los inmigrantes son los que no pertenecen a la comunidad, muchas veces incluso aunque sean inmigrantes regulares). Esta simplificación es necesaria para los discursos tanto oficiales como no oficiales acerca de la inmigración.

3) En el debate acerca de la inmigración se pueden distinguir dos discursos oficiales, o sea, dos discursos defendidos abiertamente por políticos (conservadores y progresistas), así como por los teóricos. El primero es el discurso del control, según el cual la inmigración en sí es un fenómeno que es necesario controlar con medidas administrativas y jurídicas (algunos ven en tal fenómeno un mal negativo e inevitable, casi como una catástrofe natural, y otros descubren en él algo positivo, como, por ejemplo, la solución a las bajas tasas de natalidad de muchos países europeos 0 una ocasión de enriquecimiento cultural). Normalmente, a ese discurso se acompaña el corolario de que es necesario luchar contra la inmigración clandestina. El segundo es el discurso de la adaptación, conforme al cual los inmigrantes deberían adaptarse a los valores o al modo de vida de la sociedad de acogida. Normalmente, a ese discurso se acompaña el corolario de que los inmigrantes que no se adaptan pueden ser "re-enviados" a su país de origen. Hay, sin embargo, un tercer discurso, que desde el punto de vista oficial es minoritario (solamente lo defienden partidos de extrema derecha y en algunos pocos casos de extrema izquierda), pero a veces está peligrosamente bien difundido entre la población europea: el discurso del rechazo, conforme al cual "nuestro país no es un país de inmigración" y, por tanto, los inmigrantes deberian todos volver a su pais (aunque normalmente se haga una excepción para inmigrantes especiales -como, por ejemplo, los deportistas- o para los que vengan de países considerados iguales o semejantes al "nuestro" -como, por ejemplo, los EE.UU., Australia, Canadá, etc.). Hay entre los discursos oficiales y el no oficial una contigüidad mayor de la que se supone normalmente: una de las tareas de este artículo es señalarla.

4) Finalmente, el debate establece una distinción entre los inmigrantes y los ciudadanos que no es simplemente jurídica (o sea, neutra desde el punto de vista valorativo), sino más bien ontológica, en el sentido de una ontología política que mira a definir la comunidad política por medio de la contraposición al Otro y que atribuye a los dos grupos diferentes estatutos éticos (y a veces hasta morales) y, por tanto, diferentes deberes y derechos.

\section{1) LA CUESTIÓN DE LA INMIGRACIÓN Y EL DISPOSITIVO}

A fin de entender mejor la cuestión de la inmigración es necesario renunciar a la tentación de reducirla a una simple cuestión de gestión de los flujos migratorios a través de un sistema de control de los mismos. Como opción alternativa podemos hablar de un régimen de migración (como lo hace Willenbücher) o utilizar el concepto foucaultiano de dispositivo. Willenbücher define el régimen de migración como "la totalidad de las reglas y prácticas jurídicas, administrativas, de control fronterizo, de policía y de política social que reglamentan la movilidad temporal, repetida o duradera entre diferentes estados nacionales" (Willenbücher 2007, 52 s.). El concepto de régimen en cuanto opuesto al concepto de sistema indica una pluralidad de actores cuyas acciones y prácticas se remiten recíprocamente la una a la otra, pero sin que haya una lógica central (sistémica) como, por ejemplo, aquélla que concibe el Estado como un sujeto unitario. La gestión de la inmigración es más bien ejercida por varias instancias que, a veces, se contradicen o se obstaculizan reciprocamente y dejan así loopholes, espacios de indeterminación jurídica y política que pueden ser disfrutados por los inmigrantes o que los colocan en situaciones de casi-ilegalidad en la cual dependen más de la benevolencia de burócratas y funcionarios públicos que de una ley cierta y objetiva.

El concepto de dispositivo amplía esta idea hasta incluir los elementos que no pertenecen a las prácticas de gestión 
de la inmigración, sino al discurso acerca de ella. Foucault indica con este término "un conjunto decididamente heterogéneo que incluye discursos, instituciones, estructuras arquitectónicas, decisiones reglamentarias, leyes, medidas administrativas, enunciados científicos, proposiciones filosóficas, morales, filantrópicas, en suma: tanto lo dicho como lo no dicho". El dispositivo posee "una función estratégica dominante" y responde a problemas que se presentan en un momento histórico determinado. "El dispositivo está siempre inscrito en un juego de poder, pero está siempre también ligado a un o a algunos límites de saber que nacen de él, pero al mismo tiempo lo condicionan. Eso es el dispositivo: estrategias de relaciones de fuerzas que soportan tipos de saber y son soportadas por ellos" (Foucault 2001, 300).

El concepto de dispositivo nos permite, entonces, pensar al mismo tiempo el régimen de migración y el saber ligado a él. En este sentido, el debate sobre la migración pertenece al dispositivo de control de la migración y no es meramente teórico o políticamente inocente. Esto aparece particularmente evidente cuando consideremos que las medidas concretas (o sea, las medidas políticas, jurídicas y de policía) tomadas en relación a la inmigración son el resultado del debate sobre ella, o sea, de la manera en que el fenómeno de la migración es descrito y en que los inmigrantes son definidos. Al mismo tiempo, el debate acaba por ser influido por las propias medidas concretas, creando un círculo vicioso o, mejor, una self-fulfilling prophecy que puede hasta llevar a un razonamiento en forma de espiral ascendente: si en el debate los inmigrantes irregulares son descritos como un posible peligro para la sociedad $y_{\text {, }}$ en consecuencia de esto, son tomadas medidas que criminalizan la inmigración clandestina, los participantes en el debate se verán autorizados no solamente a reafirmar su caracterización de los clandestinos como posiblemente peligrosos, sino a describirlos como siendo realmente peligrosos para la sociedad, provocando tal vez medidas aun más restrictivas 4 .

En este contexto, deberíamos distinguir dos aspectos del "problema" de la inmigración y dos diferentes ámbitos en los cuales los discursos mencionados se aplican. El primero es el de la "integración" de los inmigrantes regulares; el segundo es el de la inmigración clandestina. En el debate político a veces los dos están entremezclados y puestos en el mismo plano, particularmente por partidos de derecha o por partidos xenófobos. La posición de tales partidos oscila entre el rechazo total de la inmigración y la posición "moderada", según la cual solamente un número limitado de extranjeros puede inmigrar y ellos tienen que adaptarse a los costumbres y a la visión del mundo de la sociedad receptora. Estas dos exigencias las mantienen también muchos teóricos, aunque no siempre con la radicalidad con la que ahora se expone. Aunque no puedan ser confundidos el uno con el otro (como lo hacen los partidos más radicales), los dos aspectos acaban por vincularse por medio de la criminalización de los clandestinos, criminalización que representa una consecuencia práctica de un discurso teórico, como veremos, y que ejemplifica la relación de condicionamiento reciproco entre saber y prácticas mencionada por Foucault.

\section{2) ¿QUIÉNES SON LOS INMIGRANTES?}

En primer lugar, debe observarse que hablar de los inmigrantes constituye una simplificación dudosa que no tiene en cuenta que el fenómeno migratorio depende de innumerables factores, de decisiones individuales y de circunstancias sociales, económicas y políticas más generales. Con certeza, no es fácil establecer cuál de tales factores es el más decisivo. Dal Lago, por ejemplo, observa que "las migraciones, como cualquier fenómeno social, son la suma de innumerables historias individuales, decisiones aleatorias, 'proyectos' parcialmente conscientes, trayectorias existenciales que, con base en la retórica científica aceptada, se disuelven en procesos colectivos y se transforman así en abstracciones" (Dal Lago 2008, 163). Por otro lado, Saskia Sassen afirma que "el individuo puede experimentar su propia emigración como el resultado de sus decisiones personales. Pero la opción misma de emigrar es un producto social" (Sassen 2006, 19). De todas maneras, estos dos autores Ilaman nuestra atención sobre el hecho de que la inmigración no depende exclusivamente de la pobreza. Muchas veces los migrantes buscan no solamente trabajo y dinero (para después volver a su país y vivir allá con un relativo bienestar), sino condiciones de vida mejores. Este fenómeno puede ser observado también en relación a las migraciones internas: muchos individuos dejan su pueblo o su pequeña ciudad provinciana para trasladarse a una metrópoli buscando no solamente trabajo y oportunidades de carrera, sino un tipo de vida que no encuentran en su 
lugar de origen. No podemos reducir a simples razones económicas las complejas motivaciones que conducen a los individuos a la decisión, muchas veces dolorosa, de dejar su lugar de nacimiento, su familia, su red de afectos y relaciones personales, para trasladarse a un lugar desconocido, que tiene un clima frecuentemente muy diferente, donde se habla otro idioma y valen otras costumbres, así como otros códigos de comportamiento y de relaciones personales, y donde ellos no poseen el amparo de su familia (aunque puedan llegar a tener el de una comunidad de compatriotas). La reductio ad oeconomiam es típica del debate y acaba por hacer de los inmigrantes individuos en busca solamente del dinero y del bienestar que se encuentran en las sociedades ricas; a partir de esta idea es posible entonces reducir la cuestión del control de la inmigración a una cuestión de gastos y beneficios y preguntarse si los inmigrantes contribuyen o no al bienestar económico del pais de acogida. Esta pregunta sobreentiende que, si éste no fuese el caso, hay una razón legítima para negarles el acceso.

Además, los gastos ligados a la entrada clandestina en paises europeos o en los EE.UU. son elevados y casi nunca pueden ser pagados por la mayoría de los habitantes de los paises donde la emigración es más fuerte, ni siquiera después de muchos sacrificios económicos. Así, los clandestinos que llegan ilegalmente a Europa después de pagar algunos miles de dólares a los "traficantes" son frecuentemente miembros de la clase media en su país y a veces se trata incluso de individuos con una alta escolaridad y buena formación profesional. El error está en considerar como única fuente de llegada clandestina los barcos que cruzan el estrecho de Gibraltar, el mar de Sicilia o el Adriático y que traen consigo individuos que huyen de la guerra y del hambre. Por ejemplo, Michael Willenbücher, citando a Harald Lederer, distingue tres maneras para entrar en la situación de clandestinidad en Alemania: 1) cruzar las fronteras ilegalmente sin papeles evitando los controles; 2) cruzar las fronteras pasando por los controles con papeles falsos; 3) entrar legalmente en el país y quedarse después de la fecha de validez del visado $(0$, también, casarse con la única finalidad de obtener un visado permanente o la ciudadanía). Los prófugos que llegan a las costas de la Europa meridional se sirven de la primera estrategia, pero hay muchos que se sirven de las otras dos, que son menos evidentes. Del mismo modo, siempre según Willenbücher, hay por lo menos siete categorias de migrantes ilegales: 1) trabajadores empleados por temporada o con un contrato temporal que se quedan en el país después que su visado haya vencido; 2 ) estudiantes que se quedan (sin visado) después del estudio; 3 ) formas de reagrupamiento familiar diferentes a las previstas por ley (que en Alemania está previsto únicamente para el cónyuge y los hijos menores); 4) divorcio antes del tiempo previsto para la concesión del visado permanente o de la ciudadanía; 5) prostitución; 6) personas que pidieron asilo y no lo obtuvieron, pero se quedaron en el país; 7) repetidas estancias breves con la finalidad de trabajar ilegalmente (cf. Willenbücher 2007, 42 s.).

Tales consideraciones nos llevan a concluir que los clandestinos no representan un grupo homogéneo y que la inmigración ilegal no posee solamente una causa económica (contrariamente a lo que piensa el propio Willenbücher), sino también una "biográfica", como vimos arriba. En este contexto hablar genéricamente de los inmigrantes y pensar que sea posible una política única de control y gestión de los flujos migratorios es, como mínimo, una simplificación engañosa (no obstante, a continuación me serviré de la expresión "los inmigrantes" a fin de reproducir los discursos usados en el debate teórico y político, ya que ellos son el objeto de este artículo).

La falta de percepción de la complejidad del fenómeno migratorio se revela también en otro aspecto característico del debate sobre la inmigración: la contradicción entre la caracterización de los inmigrantes como individuos poderosos y peligrosos, por un lado, y como individuos débiles y parásitos, por otro. Bonnie Honig observa que "en el pensamiento político clásico, el extranjero es generalmente considerado una amenaza de corrupción que debe ser dejada afuera o contenida por amor a la estabilidad y a la identidad del régimen" (Honig 2001, 1 s.). Esta identificación del extranjero con algo de problemático y amenazador sigue siendo una característica del debate contemporáneo sobre la inmigración. En esta visión, el extranjero trae consigo un peligro para la comunidad por el simple hecho de ser extranjero. La posibilidad de que él pueda traer consigo nuevas energías y fuerzas vitales para la comunidad no es en absoluto considerada, aunque las estadísticas económicas prueben que los inmigrante representan casi siempre un beneficio para el país en cuestión (por ejemplo, en Italia los inmigrantes constituyen el 6\% de la población y son responsables por el $10 \%$ del PIB) y 
aunque en algunos paises (como los Estados Unidos) los inmigrantes fueran celebrados en un tiempo como la linfa vital capaz de fortalecer y rejuvenecer el pais. La razón de que no se tomen en consideración esos datos y circunstancias está en el hecho de que el debate contemporáneo sobre la inmigración no se refiere a cuestiones empíricas, como la contribución de los inmigrantes al PIB nacional, sino a cuestiones estrictamente políticas. Ali Behdad Ilama nuestra atención por la paradoja de considerar a los inmigrantes como seres débiles y desprovistos de todo (los ejércitos de pobres hambrientos que llegan a nuestras fronteras sin nada fuera de su cuerpo literalmente desnudo) y al mismo tiempo como seres amenazadores capaces de destruir nuestra sociedad con su simple presencia; la paradoja de ver en ellos a parásitos que disfrutan los servicios de nuestro Estado social y al mismo tiempo individuos que nos roban el trabajo con su disponibilidad a trabajar en ritmos y en condiciones que ningún europeo aceptaría (Behdad 2005, citado en Honig 2001, 77).

Al mismo tiempo, también la consideración de los efectos positivos de la inmigración en términos económicos (la mencionada reductio ad oeconomiam) o de las nuevas energías aportadas a la sociedad de acogida supone juzgar a los inmigrantes a partir únicamente de su contribución al bienestar del país que los recibe (Honig 2001, 46 y 99). Sea cual sea el punto de vista (el de la amenaza o el de la contribución positiva), los inmigrantes son considerados solamente de manera instrumental y desde la perspectiva egoista de la comunidad que los acoge ("¿nos traerán perjuicios o beneficios?"). Desde esta óptica, los inmigrantes dejan de ser juzgados por aquello que ellos mismos son, es decir, seres humanos, y se tornan meros medios para el beneficio de la sociedad o meros instrumentos de desagregación social. A partir de tal perspectiva, cualquier intento de conducir la discusión en términos de derechos humanos se torna imposible (sobre este aspecto volveré en seguida), como se vió con ocasión de la restricción masiva del derecho de asilo en la UE y en los países europeos en general. Para justificar esta restricción de derechos, se recurre normalmente a dos tipos de discursos: el del control y el de la adaptación. En seguida analizaré un ejemplo de discurso que reúne la retórica del control y aquella otra de la adaptación. Lo que torna interesante este ejemplo es el hecho de haber sido formulado en un contexto en que lo que estaba en discusión no era la migración masiva de los últimos años, sino justamente la restricción del derecho de asilo debatida en el parlamento alemán en los años noventa de la centuria pasada.

\section{3) "AdÁPTENSE o VÁyANSE"}

En 1992, la filósofa húngara Agnes Heller (a su vez una migrante que dejó su país para refugiarse en los EE.UU.) publicó en el semanario alemán Die Zeit su "Diez tesis sobre el derecho de asilo" ${ }^{5}$. Heller empieza afirmando que "la emigración es un derecho humano, la inmigración no" y que son los miembros de la familia quienes deciden quién puede quedarse en la casa y quién debe quedarse fuera. La comparación de una sociedad compleja con un núcleo familiar parece problemática, pero no para Heller, quien afirma que "el reglamento doméstico [Hausordnung] de los estados modernos o de la casa europea recién constituida no necesita diferenciarse del reglamento doméstico en general", el cual reglamenta las condiciones mínimas para la convivencia, que está ligada a deberes u obligaciones. Heller, por tanto, considera la imagen de la casa común europea como algo más que una simple analogía. Sin embargo, ella no ofrece ningún argumento para esta visión extremadamente problemática de la comunidad política como núcleo familiar y del Estado o de la Unión Europea como casa (sobre todo si consideramos que cuando ella escribió este texto el proceso de integración aún no era tan avanzado como hoy y los propios ciudadanos europeos no disponian de todas las posibilidades de movilidad en los paises de la Unión que poseen actualmente ${ }^{6}$.

Los miembros de un Haushalt, de un núcleo familiar, tienen el deber de abrigar individuos que se encuentren en una situación de necesidad, pero solamente por el tiempo en que tal necesidad perdura: "Ya que los miembros de un núcleo familiar acaban por vivir de manera menos agradable en el momento en que acogen extranjeros en su casa (a no ser que los extranjeros se hagan cargo de tareas domésticas desagradables o pesadas), la decisión de acoger extranjeros en casa y en qué condiciones fue siempre difícil" (cursivas de AP). En otras palabras, los inmigrantes pueden quedarse desde el momento en que aceptan las tareas (los trabajos) desagradables y pesados, o sea, las tareas que probablemente los miembros de la familia, o sea, los ciudadanos de la "casa" europea, no quieren cumplir (como cuidar de un familiar anciano o enfermo, realizar la limpieza de la 
casa o de la ciudad, coger hortalizas en los invernaderos, etc.) y que, de hecho, en nuestra sociedad son ejercidas hoy por inmigrantes regulares y clandestinos ${ }^{7}$. A despecho del título del artículo, no se cuestiona el hecho de que tales inmigrantes puedan poseer un derecho de asilo ya que, como vimos, la única cosa que la autora subraya es que no hay un derecho a la inmigración. Es verdad que ella afirma que hay para los miembros de la familia un deber de abrigar personas necesitadas, pero es un falso deber, ya que depende de las decisiones de los propios miembros de la familia. Además, el "deber" de acogida es limitado en el tiempo: "tanto cuanto dura la situación de necesitad". La cuestión es: ¿qué hacer con los inmigrantes que provienen de países adonde "la situación de necesitad" es permanente, como en el caso de los que escapan de una situación de necesitad económica (o de una situación política aparentemente sin salida como los kurdos, los palestinos, los tibetanos, etc.)? ¿poseen un derecho de asilo o dependen de la buena voluntad de los miembros de la familia?

Los deberes que Heller atribuye a aquéllos que ella denomina "dueños de casa" [Hausherren] son deberes que ella califica "éticos" (y no "morales"8) y a los cuales no corresponden derechos, como en el caso de los deberes imperfectos o condicionados de Kant (el deber de benevolencia me impone ayudar a los otros, pero ellos no tienen derecho a mi ayuda). Los únicos que tienen deberes incondicionados son los inmigrantes, de los cuales se espera que sigan el reglamento doméstico. Heller identifica tres principios que constituyen tal reglamento y que, por tanto, deben ser satisfechos por los "huéspedes". El primero consiste en obedecer a las leyes. El segundo, en seguir las leyes no escritas de la sociedad de acogida, "por ejemplo, los imperativos de higiene y cortesía", así como en aprender el idioma del país. El tercero estriba en contribuir al bienestar de la casa.

El primer deber es, como mínimo, redundante, ya que la obediencia a las leyes es algo que se exige a todos, no exclusivamente a los inmigrantes. Desde este punto de vista, el problema de la criminalidad de los inmigrantes no es un problema ligado a la inmigración en sí, sino a la capacidad del Estado de garantizar el orden público. No debemos caer en los errores opuestos de criminalizar a todos los inmigrantes y simultáneamente considerarlos a todos víctimas de circunstancias superiores independientes de ellos (la pobreza, la ausencia de oportunidades, la falta de educación o hasta la cultura de su grupo). Exigir que los derechos jurídicamente garantizados de los menores o de las mujeres sean respetados por sus padres o sus maridos no significa imponer nuestros valores occidentales, sino defender a los individuos. Los relativistas culturales que se oponen a esta visión son los mismos que se indignan cuando la violación de tales derechos es efectuada por "miembros de la familia". 0 ellos reconocen su contradicción y mudan su posición, o acabarán por defender que no podemos exigir de los inmigrantes lo que exigimos de nuestros conciudadanos (sería una inversión especular de la posición de Heller). En este último caso, su actitud acabaría por ser más paternalista e irrespetuosa contra los inmigrantes que aquélla de sus adversarios presuntamente eurocéntricos.

El tercer deber remite a un aspecto sobre el cual volveré más tarde: el papel de los inmigrantes en la economía de nuestra sociedad. El segundo es típico del discurso de la adaptación: "ellos" pueden venir y hasta quedarse aquí, pero deben adaptarse a nuestro modo de vida. Retomando la analogía helleriana con la casa, los inmigrantes pueden entrar, pero no pueden ensuciar los muebles (normas higiénicas) y deben comportarse bien con las viejas abuelas a las que no les gusta ver desconocidos en su habitación (normas de cortesía). No estoy usando la imagen de las viejas abuelas por casualidad, ya que la propia Heller (en su tesis novena) hace un paralelo entre los inmigrantes y los niños: "los niños tienen que aprender las condiciones mínimas de las relaciones humanas, o sea, las leyes de su civilización". De la misma manera, evidentemente, los inmigrantes tienen que aprender las leyes de la sociedad receptora. Heller reconoce que ese proceso de aprendizaje puede ser doloroso y afirma: "Es deber del dueño de casa aliviar esos dolores y ofrecer una indemnización para ellos. La indemnización más importante consiste en un mayor respeto. La obligación moral que liga al extranjero a este deber se diferencia de aquélla del dueño de casa, pero [tales obligaciones] se corresponden una a la otra. Deben llegar a ser simétricas en su relación tanto cuanto sea humanamente posible" (Heller 1992).

Al "deber" del dueño de casa no corresponde un derecho del inmigrante; al contrario, le corresponde un deber igual. Pero hay una asimetría en la relación descrita por Heller: el "dueño de la casa" se comporta de manera paternalista en relación a los "huéspedes" que deben ser educados (doloro- 
samente) a renunciar, por lo menos en parte, a su identidad originaria; en cambio, ellos recibirán hospitalidad y respeto (que evidentemente no es algo debido).

En el discurso de Heller se mezclan, pues, las dos dimensiones del control y de la adaptación: los dueños de la casa tienen el deber de controlar a quienes ellos dejan entrar y de educarlos para comportarse de manera conforme a las reglas escritas y no escritas de la casa; a su vez, los huéspedes tienen el deber de adaptarse a las reglas y de renunciar a aquella parte de su identidad que contrasta con ellas. Al mismo tiempo, la autora se sirve de la importante analogía casa-sociedad o casa-Estado. Aunque esta analogía, hasta hoy muy utilizada en el debate, sea engañosa, ella nos ayuda a desvelar algo que se queda en el ámbito del no-dicho y que está presente en este tipo de discurso. Al exigir que los "huéspedes" respeten las reglas (escritas y no escritas) y se adapten a ellas, se sobreentiende que los "miembros de la familia" respeten siempre tales reglas (y esto es evidentemente falso) o que ellos puedan violarlas sin que por eso sean expulsados de la casa.

Esto queda aún más claro si consideramos la pretensión de que los inmigrantes "se adapten a nuestras leyes", o sea, a las reglas escritas, pretensión que, como vimos, no tiene mucho sentido, pues las leyes no piden que nos adaptemos a ellas en el sentido de aceptar sin reservas su justificación y su finalidad, sino que se las obedezca. Es exactamente la mera obediencia a las leyes lo que se exige a los "miembros de la familia". Nadie, por ejemplo, exigiría de un funcionario público católico fiel al dictado de Roma que acepte con entusiasmo la ley que prevé el matrimonio gay, sino que aplique tal ley independientemente de su opinión sobre ella. Por tanto, exigir de los inmigrantes más que la simple obediencia a las leyes, a las reglas escritas, revela una preocupación no con las reglas, sino con el hecho de que ellos no son "miembros de la familia". En otras palabras: nadie exige de los "miembros de la familia" que respeten las reglas de la casa como condición para quedarse. Si la preocupación fuese de verdad por el respeto de las reglas, se deberian expulsar de la casa a los miembros que no las respetasen. En realidad, la cuestión no concierne a las reglas, como a este tipo de discurso le gustaría que creamos, sino al hecho de que los inmigrantes (los "huéspedes") no son "nosotros", son otros, son "el Otro". Detrás del discurso del respeto de las reglas y de la adaptación se esconde el discurso del rechazo de la alteridad, o sea, el tercer discurso, el discurso no oficial que ya se mencionó arriba.

\section{4) Etnia, CUltura, cosmopolitismo}

Hay partidos políticos, hombres políticos y simples ciudadanos que defienden una verdadera visión étnica del concepto de ciudadanía: los derechos sociales y políticos deben ser garantizados solamente a los italianos, a los españoles, etc., partiendo del presupuesto de que esos últimos pertenecen a una unidad homogénea constituida étnica y culturalmente. En esta visión, un marroquí o un colombiano que haya obtenido la ciudadanía española, por ejemplo, no es un español de verdad, sino solamente alguien que usurpó la calificación de español sin pertenecer a la verdadera hispanidad. En esta visión no es suficiente querer ser miembro de la comunidad política, pues la pertenencia a ella es establecida de una vez por todas por el nacimiento, por el hecho de haber nacido de padres italianos, españoles, etc. Ciudadanía y nacionalidad son definidas de manera étnica, sin dejar ningún resquicio para la inclusión en la comunidad política de nuevos miembros que quieran entrar en ella dejando su comunidad originaria.

La explicación más común para la popularidad de esta visión se remite a los problemas que la globalización habría provocado en nuestras sociedades. La xenofobia, el racismo y el cerrarse ante la inmigración serían la reacción de individuos asustados por las transformaciones ligadas a la mundialización de la economía, por la internalización del mercado de trabajo, por los efectos dominós de las diversas crisis financieras, etc. A los problemas y crisis económicos se añadiría en suma una crisis de identidad individual y colectiva que suscitaría tensiones destinadas a descargarse en explosiones de odio $u$ hostilidad contra los inmigrantes ${ }^{9}$. Conforme a la lectura de Roberto Alejandro, hay aquí una inversión del fenómeno del resentimiento descrito por Nietzsche, pues el objeto principal de tal sentimiento ya no es hoy el privilegiado y el poderoso, sino el débil y, particularmente, el otro, cuya función principal es la de confirmar nuestra identidad colocándonos en el mismo lado de los ricos y poderosos. Los inmigrantes sin papeles que viven bajo los puentes y en las estaciones del metro representan un punto de vista referencial que 
nos permite constatar - cada vez que nuestros caminos se cruzan con ellos- que "no somos ellos" (Alejandro 1998, 26). Esta consideración es importante porque nos Ilama la atención sobre el hecho de que, desde este punto de vista, la comunidad se define al final negativamente, o sea, a través de la exclusión de los diferentes, de los otros. Desde este punto de vista, el discurso del rechazo del Otro se torna un elemento necesario para la definición de la propia comunidad y muestra cómo el debate sobre la inmigración puede tornarse rápidamente en un discurso ontológicopolítico, o sea, en un discurso referente a la definición de un ente político, en este caso, la comunidad política. En un momento de crisis de las narrativas tradicionales alrededor de las cuales se articulaba la definición de una comunidad (crisis desencadenada por los fenómenos ligados a la globalización, por la propia inmigración y, sobre todo, por la creciente integración internacional de los varios países que lleva a una mayor interdependencia y sustrae poder a los gobiernos nacionales dejando desorientados a los ciudadanos), muchas personas buscan nuevos elementos de cohesión y nuevos discursos fundacionales. La identificación de un enemigo común (los inmigrantes) puede ser una estrategia de este tipo, como se ve bien en el caso de partidos abiertamente xenófobos como la Lega Nord, el BVÖ, el FN, etc. ${ }^{10}$.

Esta posición radical no es normalmente defendida en el debate teórico acerca de la inmigración (debate en el cual, antes, muchas veces se defiende una visión de comunidad inclusiva, no exclusiva del Otro). Pero se sustituye por una posición igualmente dudosa, ya que está basada sobre un concepto altamente cuestionable de comunidad política. La visión étnica en su versión más radical tiene algo en común con las teorías de la raza: las identidades individual y social de las personas son para ella una cuestión biológica. El simple hecho de haber nacido de padres italianos o españoles hace de alguien un italiano o un español auténtico. Esta idea puede parecernos absurda, mas está en la base del ius sanguinis que hasta hoy decide de la atribución de la ciudadanía en muchos estados europeos y extraeuropeos (así, por ejemplo, los tataranietos de inmigrantes italianos en Brasil pueden obtener la ciudadanía italiana aunque no tengan ninguna relación con Italia, ni conozcan su leyes -escritas y no escritas- y ni siquiera hayan visitado una vez el país). Pero hay una versión más sofisticada de la visión étnica, que sustituye el término "etnia" por el de "cultura". Éste es el caso de las teorías que se conocen bajo la denominación de "multiculturalismo". No es posible enfrentar en este contexto el tema tan complejo del multiculturalismo. Lo que me gustaría señalar es su influencia en el debate sobre la inmigración. Desde la perspectiva multiculturalista hay una pluralidad de culturas o de grupos definibles culturalmente (según elementos que los distinguirían de otros grupos, como pueden ser el idioma, la religión, etc.) que parcelan el mismo espacio geopolítico (normalmente un Estado) y que conviven de manera más o menos separada una al lado de la otra (multiculturalismo como mosaico, como lo llaman M. M. Slaughter o Seyla Benhabibi1). El multiculturalismo exige el reconocimiento político y jurídico de las diferencias culturales y lucha contra cualquier intento de asimilación forzada (violenta o no); celebra, por tanto, tales diferencias como algo positivo que merece ser mantenido ${ }^{12}$. Las teorías multiculturalistas parten de la idea de que una cultura es algo estable e inmutable, algo con límites claramente definidos, cerrado en sí mismo como una bola de billar, para usar la imagen de James Tully (Tully 1995, 10). El determinismo biológico de las antiguas teorías racistas es sustituido por el determinismo cultural, según el cual los individuos pertenecen a una cultura que determina de manera inexorable su carácter y su actitud. Las diferencias individuales y biográficas son desconsideradas en nombre de una reductio ad culturam que hace de cada ser humano no un individuo, sino un miembro de su comunidad cultural. A esta visión Benhabib contrapone la idea de que las propias culturas humanas son "creaciones, recreaciones y negociaciones continuas de límites imaginarios entre 'nosotros' y lo(s) 'otro(s)'" (Benhabib 2002, 8). La consecuencia de tal idea es que también la formación de la identidad individual en el contexto de una determinada cultura pierde cualquier carácter determinista. La formación de la identidad individual es posible solamente en el contexto de una cultura, a través de la apropiación por parte del individuo de los "códigos" lingüísticos, morales, etc., propios de una determinada comunidad. Sin embargo, este proceso sucede en el nivel simbólico, o sea, en el ámbito de la narrativa que constituye aquella cultura ( $y$, por tanto, su identidad colectiva) y de la narrativa individual a través de la cual cada uno se define como sujeto ${ }^{13}$. El proceso no sucede en un nivel ontológico, por así decir, pues en caso contrario nadie podría salir de su cultura ni desviarse de ella (por ejemplo, al fin de adaptarse a la cultura de su nuevo país de acogida como lo exige el discurso de la adaptación). Ahora bien, cada narrativa (colectiva o 
individual) está sujeta a transformaciones y puede ser modificada en varias circunstancias (una posición defendida curiosamente hasta por un multiculturalista como Charles Taylor $\left.{ }^{14}\right)$. Desde este punto de vista, la identidad cultural de un grupo es algo mutable. La transformación puede ocurrir por causas endógenas (o sea, a partir del interior del grupo, por iniciativas de los propios miembros, como opina Taylor) o por causas exógenas (o sea, por el contacto con otros grupos culturales y la consecuente influencia reciproca, o hasta por absorción de uno por el otro). En esta perspectiva, el propio término "identidad cultural" debería ser usado solamente en sentido metafórico, por analogía con el concepto de identidad individual. Pero, el discurso de la adaptación parte justamente de la existencia de, por lo menos, dos identidades culturales: la de la sociedad de acogida y la de los grupos a los cuales pertenecen los inmigrantes. Tal discurso afirma que la identidad cultural de la sociedad de acogida no debe (en sentido normativo) modificarse por causa de la inmigración; los inmigrantes son quienes antes deben modificar su identidad cultural individual para adaptarse a ella.

El discurso de la adaptación o de la re-educación cultural es tan dominante que casi nadie plantea una pregunta aparentemente obvia: ¿por qué los inmigrantes deberían renunciar (totalmente o parcialmente) a su cultura de origen y asumir aquélla del país de acogida? Si la cultura es tan esencial en la definición de la propia identidad individual y social, como afirman las teorías de la identidad cultural, es necesario preguntarse cómo puede exigirse a los individuos que modifiquen tan radicalmente su identidad y que lo hagan justamente en nombre de la identidad cultural (del país de acogida). Al final, parece que no hay otra razón que el mero hecho de que "nosotros" no queremos renunciar a nuestra (porosa, transitoria y mudable) identidad cultural y exigimos simplemente que "ellos" renuncien a la suya. En suma, exigimos que dejen de ser otros para tornarse como nosotros y para esta exigencia no hay otra razón que nuestro miedo o nuestro rechazo de la alteridad.

Si el discurso de la adaptación puede frecuentemente esconder un rechazo de la alteridad en nombre de una identidad étnica o cultural, eso no significa que siempre las cosas sean asi. A veces, lo que se pide de los inmigrantes es que se adapten a valores más universales que los de su sociedad de origen. En suma, se pide que ellos abran su mente y su visión del mundo a un horizonte más ancho y más plural, más tolerante, menos fijado en las particularidades culturales. Se trataría, por tanto, de otra forma de adaptación, más respetuosa de la alteridad que aquélla del discurso tradicional del "se tornen como nosotros o se vayan".

Julia Kristeva, en su libro Nations without Nationalism (1993), plantea la cuestión de qué es lo que motiva a los inmigrantes a escoger una determinada sociedad (en su caso, la francesa) como comunidad de acogida, además de las mayores oportunidades económicas y del eventual conocimiento del idioma (cuando su país de origen fue colonia de su país de llegada). En el modo de plantear la cuestión, parece excluir que la falta de oportunidades económicas y el colonialismo (dos razones interconectadas, pues la primera depende casi siempre del segundo) sean razones suficientes para que las sociedades de destino acojan a los inmigrantes en cuestión ${ }^{15}$. Kristeva (y no solamente ella) pregunta a los inmigrantes si no hay algo típicamente francés (en su caso) que les haya conducido justamente a Francia y no a otro país (Kristeva 1993, 60), como, por ejemplo, los valores cosmopolitas y el respeto del otro y del propio extranjero que caracterizarian la sociedad francesa ${ }^{16}$. Si la derecha (extrema y moderada) exige que los inmigrantes se asimilen o se adapten a la sociedad francesa y a sus valores tradicionales, lo que Kristeva parece exigir es que ellos se adapten al cosmopolitismo presumidamente típico de tal sociedad.

Lo que se espera de los inmigrantes aquí es prácticamente lo mismo que en el caso del discurso más tradicional, o sea, que se tornen iguales a nosotros (cosmopolitas, tradicionalistas o lo que sea) o retornen de donde vinieron. Es verdad que los valores cosmopolitas son más universales que los valores tradicionales queridos por la derecha; por tanto, la exigencia avanzada por Kristeva no parece tener el carácter de una invitación a la asimilación completa en la sociedad francesa (en el sentido de un nacionalismo más o menos fuerte). Lo que ella espera de los inmigrantes es que ellos acepten valores que no son propios de sus culturas de origen, sino de la sociedad de acogida. La aceptación de semejantes valores constituye así la condición para ser aceptados como verdaderos miembros de la comunidad, sea como ciudadanos (en el caso de los naturalizados), sea en la condición de extranjeros sin derechos políticos.

Lo que torna tan interesante esta exigencia es el hecho de que, más de una vez, ella no es planteada en referencia 
a los que ya son ciudadanos, a los nativos. Kristeva y los otros teóricos de la adaptación parten del presupuesto de que los franceses, los españoles, los italianos, etc., apoyan firmemente los valores cosmopolitas o democráticos o hasta nacionales (aunque no esté muy claro lo que serían valores nacionales). Ahora bien, tal presupuesto me parece altamente dudoso ${ }^{17}$. Al contrario, la propia manera en que se conduce el debate sobre la inmigración en los países europeos parece demostrar cuán poco peso poseen de hecho en ellos los valores universales del cosmopolitismo, de los derechos humanos y hasta de la democracia. De facto, hay una profunda discrepancia entre el presunto cosmopolitismo europeo y la realidad social, económica y jurídico-política. Intentaré señalar tal discrepancia partiendo de los conceptos de ciudadanía y de persona.

\section{5) Ciudadanía, Persona, no-persona}

El concepto de ciudadanía es un concepto extremamente flexible. Por ejemplo, el término puede indicar el status jurídico de personas, un contrato que reúne a los ciudadanos en el respeto de las leyes de la comunidad o la práctica de virtudes cívicas (Alejandro 1998, 9). Rainer Bauböck asume una perspectiva republicana y vincula la ciudadanía a una "participación relevante" que tenga como objeto "el interés del bien común" del Estado en cuestión (Bauböck 2006, 46). Esta participación puede ser vista como una manera de practicar la ciudadanía. Como destaca William J. Meyer (Meyer 1998, 76), la posesión del status de ciudadano es la condición necesaria para el ejercicio de la práctica de la ciudadanía (entendida como práctica de virtudes o como relación de mutua toma de responsabilidad entre los ciudadanos): "No se puede practicar verdaderamente la ciudadanía sin ser un ciudadano" (Meyer 1998, 76). Pero, precisamente eso es lo que en la "retórica de la adaptación" se espera de los inmigrantes: que practiquen la ciudadanía sin ser ciudadanos, como condición previa para ulteriormente obtener el status de ciudadanos. Intentemos, entonces, entender mejor los dos conceptos de "status de ciudadano" y de "práctica de la ciudadanía".

a) En relación al primero, podríamos recurrir al concepto de persona. La persona es una construcción jurídica, como subraya Kelsen, que la define como "la unidad personificada de las normas jurídicas que atribuyen deberes y derechos al mismo hombre" (Kelsen 1975, 198). Hay determinados deberes y derechos que constituyen un tipo específico de persona, a saber, la persona del ciudadano. Los deberes y derechos en cuestión son primeramente de naturaleza politica, ya que los de naturaleza civil y social pueden ser atribuidos también a personas que no sean ciudadanos, como, por ejemplo, a extranjeros que se encuentren en el país sin poseer la ciudadanía y que pueden pertenecer a diferentes categorias: turistas, estudiantes, trabajadores temporáneos, asilados, residentes de larga duración. Tomas Hammar acuñó, como es sabido, el término denizens (que en la lengua cotidiana indica simplemente los moradores de un lugar, aunque también un término técnico para los extranjeros que en el Common Law inglés recibian prerrogativas propias de los ciudadanos ${ }^{18}$ ) para indicar justamente a los residentes de larga duración que aún no poseen los derechos de ciudadanía, pero disfrutan de los derechos civiles y sociales (Hammar 1990, 15).

Hay todo un debate sobre la cuestión de la concesión de derechos y deberes políticos a los no-ciudadanos (cf. Bauböck 2006, Velasco 2010) -debate en el que se incluyen también medidas concretas como la concesión del derecho de voto a los extranjeros (europeos o hasta extra-comunitarios) en algunos países- mas no es él lo que nos interesa en este contexto ${ }^{19}$. Lo que nos interesa es, más bien, la constatación de una tendencia presente en algunos países europeos como, por ejemplo, Italia, a saber: la tendencia a negar algunos derechos civiles y sociales a los inmigrantes clandestinos, empezando por el derecho de asilo. Así, si por un lado la línea de separación entre ciudadanos y denizens se hace cada vez más sutil en la teoría y en la práctica, por otro, aumenta la distinción entre los inmigrantes regulares y los irregulares.

Es sabido también que Hannah Arendt señaló que los derechos humanos dejan de ser garantizados justamente en el momento en que los individuos que necesitan protección no presentan otra característica que su humanidad por haber perdido su ciudadanía (Arendt 1987, vol. 2, 392438). En el caso de que sean detenidos, los apátridas y los sin papeles que arriban a las costas europeas o cruzan ilegalmente las fronteras continentales son casi siempre reunidos en campos o centros de detención (que en Italia son llamados cínicamente "centros de acogida") para ser reenviados inmediatamente para el último país de donde procedieran sin que se haya incoado un verdadero procedi- 
miento para averiguar su situación y analizar una eventual petición de asilo. Perdieron su ciudadanía original, si no formalmente, por lo menos prácticamente (como en el caso de los prófugos que se fugan de guerras civiles 0 de persecuciones étnicas o religiosas), o destruyeron sus papeles con la esperanza (vana) de no ser reenviados a su país de origen. Al llegar aquí, no son iraquies, turcos, argelinos, sudaneses, etc., sino meramente seres humanos. Pero, justamente por este hecho, por no ser defendidos por su pasaporte, por no poder dirigirse a su consulado, son privados de los derechos civiles y sociales, con la excepción del derecho a la vida (aunque haya casos en que en el proceso de expulsión algunos padezcan maltratos que a veces conducen a su muerte). Pero, también el derecho a la vida es respetado solamente de manera formal: la policía - los funcionarios que se ocupan de repatriarlos cuidan de su vida únicamente en el sentido de no dejar que ellos mueran mientras están bajo la "protección" jurídica del país que los expulsa, pero se desinteresan completamente de su destino una vez llegados nuevamente al país de partida o al país de origen. Solamente cuando existe interés y empeño de organizaciones no gubernamentales se hacen peticiones formales de asilo y se inician los procedimientos correspondientes.

Esta actividad de las ONGs es particularmente importante desde el punto de vista de la defensa del carácter democrático de nuestros países, que está estrictamente ligado a la reclamación de los derechos. Bonnie Honig sostiene que "la democracia es una forma de política en la que el poder no es recibido por súbditos agradecidos, sino que es tomado, redistribuido, revitalizado y recirculado por medio de la libertad, o sea, a través de la acción política popular". Desde ese punto de vista, "la práctica de reclamar derechos y privilegios antes de aguardar su concesión por parte de un poder soberano es una práctica esencialmente democrática" (Honig 2001, 99). La historia de la ciudadanía fue siempre una historia de luchas para la ampliación de la esfera de derechos individuales y del número de las personas que disfrutaban de ellos, como Thomas Marshall mostró en su celebérrimo Citizenship and Social Class (1950). Casi siempre tal proceso de ampliación encontró la resistencia de los grupos que hasta el momento eran los únicos que disfrutaban de los derechos en cuestión y que, por tanto, podemos definir como privilegiados. Hoy, los privilegiados en este sentido son los ciudadanos de los países metropolitanos objeto de migración. Ellos tienden, en muchos casos, a negar a los inmigrantes los mismos derechos disfrutados por ellos mismos: no solamente los derechos políticos (hay no obstante, como ya vimos, un proceso de inclusión creciente de los denizens y de otros inmigrantes legales), sino también muchos de los derechos sociales (empezando por los vinculados al trabajo y acabando por los relativos a los servicios sociales estatales) y hasta civiles (como en el caso de la negación del derecho de asilo). Este proceso de negación de derechos acompaña a la criminalización de los clandestinos, sobre la cual volveré en seguida.

b) Si consideramos lo que significa "práctica de la ciudadanía", percibiremos la dificultad de llegar a una definición indiscutida. Sin embargo, desde la óptica de la retórica de la adaptación (y aún más desde la retórica del rechazo) es evidente que no puede limitarse a la mera obediencia a las leyes. En este sentido, se remite, más bien, al concepto de virtud cívica. El buen ciudadano no es el que se limita a respetar las leyes (ése sería a lo mejor un ciudadano honesto), sino el que posee determinadas virtudes que hacen de él un buen miembro de la comunidad política.

Las virtudes cívicas poseen un carácter instrumental: los ciudadanos deberían poseerlas porque contribuyen a la preservación y/o a la prosperidad de la sociedad y no porque contribuyan al perfeccionamiento moral del individuo. En algunos casos pueden incluso exigir del ciudadano acciones contrarias a su moralidad personal (como resaltó Maquiavelo -y no solamente en el caso del príncipe 0 del gobernante ${ }^{20}$ - y cabe además recordar que Rousseau destacó con claridad el contraste entre el mandamiento cristiano del amor universal y el imperativo patriótico de amar a los conciudadanos y, eventualmente, odiar a los enemigos de su país).

Hay virtudes que se refieren a la comunidad política en general, pues sin ellas la existencia de cualquier comunidad pudiera quedar amenazada: lealtad, tendencia a obedecer las leyes aún cuando no hay peligro inmediato de castigo, disponibilidad a sacrificarse por la comunidad, coraje, disponibilidad a asumir responsabilidades públicas, interés por el bien común, etc. Coinciden con las virtudes republicanas, ya que el interés primario del republicanismo es la salvaguarda de la república y no los intereses y el bienestar individuales. Hay otras virtudes que caracterizan las sociedades liberales: tolerancia, disponibilidad al diálogo, 
respeto de los derechos ajenos, capacidad de escoger los representantes políticos según sus talentos, disponibilidad

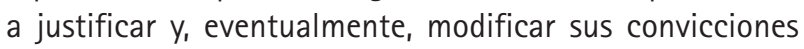
relativas a temas públicamente relevantes, etc. ${ }^{21}$. Éstas bien que podrían ser las virtudes exigidas por Kristeva para los ciudadanos de su sociedad cosmopolita.

Sin duda se trata de actitudes deseables y una teoria de la ciudadanía democrática o republicana debería ser incluida entre las condiciones para el florecimiento de una sociedad democrática y/o republicana. Pero la cuestión aquí es otra: el discurso de la adaptación exige de los inmigrantes estas virtudes 0 , por lo menos, que hagan un esfuerzo para poseerlas, pero no se posiciona en relación a los ciudadanos, a los "miembros de la familia". Cuando un imán islámico pronuncia una prédica llena de odio contra los gay "pervertidos y blasfemos", los políticos y los comentaristas en los periódicos se indignan justamente y le recuerdan que en nuestra sociedad no hay espacio para tales manifestaciones de intolerancia; pero, si un obispo o un cardenal invita a la discriminación jurídica de los gay, define la homosexualidad como una abominación u organiza una manifestación de miles de personas contra la igualdad de derechos de los homosexuales, casi nunca la indignación llega al mismo nivel y a la misma intensidad; más bien, habrá con certeza alguien entre los mismos políticos 0 periodistas que tanto se indignaron contra el imán que defenderá el derecho a la libertad de expresión del prelado en cuestión. Cuando un marido o un padre proveniente, por ejemplo, de un pais africano maltrata a su mujer o a su hija, hay quien invoca su expulsión del pais por su incapacidad manifiesta para aceptar nuestros valores; pero, nadie hace lo mismo cuando el marido o el padre violento son compatriotas: en este caso se invoca simplemente un castigo conforme a la ley. Si llamamos la atención por esta disparidad, la respuesta probablemente sería que el prelado homófobo o el compatriota violento no pueden ser expulsados porque son ciudadanos. Evidentemente, el hecho de ser ciudadano representa una especie de salvoconducto para descuidar las virtudes, los valores y los ideales que -si creyéramos en las teorías de la identidad cultural y en la retórica del discurso de la adaptación- deberían constituir no solamente el núcleo inmutable de nuestras sociedades, sino la base de nuestra identidad colectiva, que los inmigrantes deberían demostrar aceptar como suyos como condición para ser ciudadanos. Esta duplicidad es la piedra de toque que nos permite revelar lo que está atrás del discurso de la adaptación y constatar la proximidad de éste con el discurso no oficial del rechazo de la alteridad y del Otro. El discurso de la adaptación (en sus variantes cultural, republicana y cosmopolita-democrática) apela a la necesidad del reconocimiento de ciertos valores y reglas para poder ser considerados verdaderos miembros de la comunidad, pero exige tal reconocimiento solamente por parte de los inmigrantes y permanece ciego ante el hecho de que los "miembros de la familia" desatienden tales virtudes, valores y reglas, aunque éstos sean definidos como imprescindibles y necesarios para mantener la identidad cultural, republicana y cosmopolita-democrática de la sociedad en cuestión. A fin de cuentas, si consideramos la homofobia del imán suficiente para expulsarlo del país, pero no deseamos la expulsión del obispo, la razón de tal disparidad no es la inaceptabilidad de las posiciones del imán, sino el hecho de que el obispo sea nuestro conciudadano. Pero así la retórica del discurso de la adaptación se revela falsa: el interés verdadero no está en los valores, los ideales y las virtudes propias de nuestra sociedad, sino en la circunstancia de que los inmigrantes son el Otro, no son "nosotros".

\section{6) Criminalización de los inmigrantes Y POST-FORDISMO}

Finalmente, vuelvo a la cuestión de la criminalización de los inmigrantes clandestinos ya que esto nos permitirá ver lo que está atrás del discurso del control.

Hubo un tiempo en que quedarse en un pais sin permiso (por ejemplo, con un visado cuya validez estaba vencida) era considerado como una infracción administrativa y como tal era castigado con una multa y solamente en algunos casos con la expulsión del país (a veces con la prohibición de volver a él por un cierto tiempo). Hoy, una situación semejante sería considerada en muchos paises europeos un crimen objeto de proceso penal. Una situación que era de mera violación de reglas administrativas se tornó en un caso criminal. Esta criminalización de los inmigrantes ilegales es tal vez lo más característico de la reacción europea al fenómeno de la inmigración: en vez de una respuesta política, se ofrece una respuesta juridica criminalizando las infracciones contra las normas de inmigración. 
Esta preocupación por el respeto de la reglas es solamente aparente, una vez que los clandestinos, en vez de pagar por su crimen en las prisiones del pais a donde inmigran ilegalmente, son reenviados al país de origen o, en la mayoría de los casos, al último pais de proveniencia (el cual, a su vez, procederá a expulsarlos y así sucesivamente, en una espiral perversa en que los individuos son tratados como paquetes postales recusados por el destinatario). Como observa acertadamente Dal Lago, "de manera paradójica, el hecho de que un extranjero no pueda ser castigado aunque sea condenado (ya que será expulsado antes de expiar la pena) demuestra cómo la necesidad social de que desaparezca es superior a aquella del derecho formal [de que sea castigado]" (Dal Lago 2008, 222).

Ahora bien, desde este punto de vista, el individuo que no posea derechos no es una persona en el sentido definido arriba, es "vida desnuda", como dice Agamben (Agamben 1995, 9 et passim) y "la sola existencia que se le reconoce es aquella de un cuerpo físico que debe ser nutrido, controlado o detenido" (Dal Lago 2008, 222). Esta observación de Dal Lago describe exactamente la situación de los clandestinos detenidos en campos o en áreas especiales en aeropuertos, estaciones, etc., a la espera de ser admitidos en el pais o, más frecuentemente, reenviados al lugar de donde salieron. Estos individuos que, al ser privados de sus derechos, no son personas, se quedan presos en una zona gris de indeterminación jurídica, agravada frecuentemente por la falta de documentos $y$, por tanto, por la imposibilidad de ser encajados en las categorías y en los esquemas de la burocracia policial.

La criminalización de los clandestinos obtuvo como único resultado el de crear una clase de individuos que no son personas (Dal Lago diría que son no-personas) y que son obligados a tornarse invisibles, no sólo en el intento de pasar las fronteras sin ser interceptados, sino también -una vez ingresados en el país- en la esperanza de no llamar la atención de las autoridades. Esta clase constituye una reserva de fuerza-trabajo barata y como tal es explotada por los "miembros de la familia" con la tolerancia de las autoridades (al final, los explotadores son conciudadanos y, como vimos, a los conciudadanos casi todo les es perdonado). Hay aquí una triple alianza perversa entre los intereses de empresarios sin escrúpulos (en la mayoría de los casos dueños de empresas de pequeño porte), los intereses de innumerables familias preocupadas en encontrar alguien que cuide de parientes ancianos o enfermos y los intereses electorales de políticos preocupados en ganar el apoyo de los unos y de las otras.

Para entender mejor la relación entre inmigración clandestina y mercado de trabajo es necesario considerar cuál fue el origen de las migraciones en la Europa de la segunda posguerra. Los paises industriales (Alemania, Francia, Bélgica) reclutaban fuerza-trabajo en los países más pobres como Italia, España, Portugal, Grecia o Turquía. Implantaban oficinas de reclutamiento en tales países y practicaban una selección físico-psíquica de los candidatos (como si se tratase de animales de trabajo: de caballos de carga, de bueyes, etc.). En la visión de los países "reclutantes", los trabajadores deberían quedarse en el país de destino solamente por un tiempo (por esto en Alemania eran Ilamados con el cínico apelativo de Gastarbeiter, o sea, trabajadores huéspedes). Naturalmente muchos de los trabajadores prefirieron quedarse donde había trabajo y condiciones de vida mejores e intentaron traer a sus familias -lo que no siempre fue fácil-. Pero la principal oposición a las medidas que decretaban la vuelta de los Gastarbeiter vino justamente de los sectores económicos interesados, o sea, en primer lugar, de la industria, ya que la sustitución cíclica del personal hubiera significado invertir cada vez ingentes recursos financieros y humanos para la formación de los nuevos trabajadores. Con el paso del tiempo, estas generaciones de inmigrantes regulares se transformaron bien en denizens bien en ciudadanos naturalizados. La situación actual es muy diferente, pues mudó completamente la situación del mercado del trabajo. No obstante, la política parece someterse más de una vez a los intereses de la economía, aunque esta vez no en el sentido de favorecer la estancia de los inmigrantes, sino, al contrario, criminalizándola.

La criminalización de los inmigrantes irregulares coincide pues con la precarización y flexibilización del trabajo. El resultado es que los inmigrantes irregulares constituyen un inmenso reservorio de fuerza-trabajo barata y dispuesta a trabajar en condiciones extremas sin reclamar, pues los clandestinos no poseen los derechos de los trabajadores regulares y ni siquiera los derechos civiles de las otras personas, una vez que su mera presencia en el país es un crimen ${ }^{22}$. Eso no significa que los gobiernos que criminalizan la inmigración clandestina tengan la intención explícita de ayudar a los empresarios sin escrúpulos que (1) 
disfrutan ilegalmente la mano de obra barata; pero evidentemente ese problema es considerado menos grave y es combatido con menor rigor e intensidad que el problema de la inmigración clandestina.

El inmigrante clandestino representa casi el paradigma del trabajador de la era post-fordista, como observa Willenbücher: "sin derechos, pagado bien por debajo del valor de la fuerza-trabajo local, puede ser cesado y sustituido en cualquier momento. Hoy, se tornó ya en muchos casos en una columna que soporta la economía: sectores enteros como la gastronomía, la agricultura, el turismo, el sector de limpieza y de la seguridad, el trabajo sexual, el cuidado de la casa y el cuidado de los enfermos se sirven de él" (Willenbücher 2007, 72). Esta figura del perfecto trabajador contemporáneo, flexible, mudo, completamente a la merced del empresario o del "dueño de la casa" (ahora en sentido literal), encarna también el tránsito de la primacía de la economía formal a la primacía de la economía informal (un tránsito que, en realidad, representa un retorno a los tiempos pre- y protocapitalistas) y la sustitución de la fábrica como lugar de trabajo por excelencia (y como lugar de agregación y articulación de los intereses comunes de los trabajadores) a espacios de trabajo en que los individuos trabajan aisladamente, muchas veces de forma escondida, o en la intimidad impenetrable de los hogares de las familias que confían a ellos el cuidado de su casa o de sus miembros ancianos o enfermos. En consideración a tales fenómenos, la criminalización de los inmigrantes ilegales obtiene menos el efecto de impedir la inmigración clandestina y acaba, más bien, por favorecer el desarrollo de la economía informal y la explotación de la fuerza-trabajo barata y sin derechos (un trabajador clandestino que sea engañado por su empresario -como pasa frecuentemente- no puede denunciarlo si no quiere ser expulsado inmediatamente del pais). Desde este punto de vista, el argumento conforme al cual los inmigrantes dispuestos a trabajar por salarios muy bajos representarian una competencia desleal para los trabajadores locales no considera el hecho de que la verdadera diferencia entre aquéllos y éstos consiste en el diferente status legal y en la diferente protección jurídica. Es interesante constatar cómo en el discurso sobre los inmigrantes clandestinos y sobre su "competencia desleal" ese aspecto es prácticamente dejado al lado y cómo la ira y el rencor populares se concentran sobre los inmigrantes explotados y no sobre los empresarios explotadores (durante el pogrom de El Ejido del año 2000, por ejemplo, a nadie le vino a la cabeza la idea de cazar de la misma manera que a los clandestinos -particularmente a las mujeres- también a los dueños de los invernaderos donde aquéllos estaban trabajando).

El discurso del control insiste sobre la necesitad de reglamentar los flujos migratorios y de controlar las fronteras. Ahora bien, la criminalización es la respuesta de un Estado que ya no sabe controlar sus fronteras (mucho menos reglamentar los flujos migratorios). Ya que el control de las fronteras se tornó imposible, el Estado decidió extender los controles a todo su territorio. Cuando el tratado de Schengen entró en vigor, las policías nacionales dejaron de efectuar los controles fronterizos, pero no dejaron de controlar a los individuos; al contrario, aumentaron los controles en el interior de los paises, particularmente en lugares de tránsito como las estaciones de ferrocarriles y autobuses, los aeropuertos, los puertos, las carreteras principales, etc., pero también en las calles de las ciudades e incluso en las casas donde residen potenciales clandestinos. El resultado es paradójico, considerando que Schengen parecía prometer una Europa sin controles y sin fronteras. La manera en que el tratado de Schengen está siendo aplicado es un buen ejemplo del régimen tal como Willenbücher lo define: el control del territorio no es confiado solamente a una agencia (por ejemplo, a una policía fronteriza europea) y depende, más bien, de las policías locales que obedecen a reglamentos y leyes nacionales diferentes. Los intentos recientes de establecer una mayor coordinación entre las autoridades policiales de los diferentes países demuestra la ausencia de un sistema de control unificado y la impotencia de las autoridades para controlar los flujos migratorios ilegales. Al mismo tiempo, en nombre de la lucha contra la clandestinidad, se aumenta el control sobre los ciudadanos y los inmigrantes regulares, adoptando formas siempre más sofisticadas de identificación (a través del recurso a parámetros biométricos, etc. ${ }^{23}$.

En resumen: el discurso del control lleva a la criminalización de los clandestinos; ésta, a su vez, conduce a un aumento vertiginoso de la economía informal y transforma una buena parte de los "miembros de la familia" en explotadores de fuerza-trabajo barata e ilegal, explotadores a su vez ilegales. Pero la única ilegalidad contra la cual se invoca la acción enérgica del Estado es aquélla de los inmigrantes clandestinos. Al mismo tiempo, el discurso de la adaptación plantea a los inmigrantes impor- 
tantes exigencias éticas al manifestar su preocupación por la integridad de la sociedad, permitiendo además que los "miembros de la familia" desatiendan los valores, ideales y virtudes presentados como necesarios para tal integridad. En ambos casos podemos constatar una duplicidad: por un lado, hay un discurso oficial que se preocupa por la seguridad y la integridad de la sociedad; por otro lado, hay un nexo entre intereses económicos y políticos ocupados en criminalizar a los clandestinos y un auténtico rechazo de la alteridad. Los discursos oficiales sirven para ocultar estos dos aspectos. Al mismo tiempo, el discurso no-oficial del rechazo abierto de los inmigrantes garantiza que los discursos oficiales puedan estilizarse contra él como discursos del todo racionales y moderados (1), y ofrece el consenso político de base necesario para realizar las medidas de criminalización y de control (2).

Obviamente, no estoy afirmando que todo eso obedece a una estrategia planeada y dirigida. Se trata, como se indicó arriba, de un dispositivo que como tal procede de manera autónoma y casi autopoiética. Los propios teóricos que defienden los discursos del control y de la adaptación no son probablemente conscientes de lo que se puede esconder tras sus posiciones. Su preocupación por la seguridad y la integridad de nuestras sociedades es genuina y merece simpatía; pero, los caminos escogidos conducen a direcciones inesperadas $y$, finalmente, inquietantes.

\section{NOTAS}

* Profesor de filosofía política en la UFSC (Florianópolis, Brasil) y migrante. Las traducciones de los textos italianos, franceses, alemanes o ingleses son mías.

1 Este aspecto es subrayado por varios autores, por ejemplo, por Dal Lago: "el problema de la inmigración comporta valoraciones fundamentales políticas y morales (relativas a cuestiones como: humanidad, igualdad, derechos) que dependen en último análisis del hecho de escoger un campo político y que deberían ser objeto de conflictos políticos" (Dal Lago 2008, 149).

2 Con el mismo punto de vista, se reproduce el mecanismo analizado por George Lakoff en varios libros, el más reciente de los cuales es Lakoff 2008.

3 Como lo remarca acertadamente Juan Carlos Velasco, "el debate sobre la inmigración, tan lleno de matices, se presta al simplismo y a la demagogia" (Velasco 2006, 9).

Recibido: 12 de marzo de 2009

Aceptado: 10 de junio de 2009
4 Un ejemplo similar de self-fulfilling prophecy es el hecho de que la repetida difusión de los prejuicios sobre otras culturas puede llevar a que tal prejuicio se vuelva realidad. Por ejemplo, si el hecho de considerar que "los inmigrantes no se quieren integrar" conduce a no proponer su participación o a obviar su opinión al planificar determinadas actuaciones, efectivamente se les está excluyendo y acabarán, por tanto, excluidos. Debo este comentario a Juan Carlos Velasco.

5 Ese texto fue comentado por varios autores, incluso por Alessandro Dal Lago (Dal Lago 2008, 153 ss.; la primera edición de este libro es de 1999).

6 Por ejemplo, en 1993, cuando fui a vivir a Alemania, a pesar de ser ciudadano italiano necesitaba de un visado y para obtenerlo debía mostrar mi capacidad de sustentarme sin recurrir a la ayuda del Estado alemán.

7 Un lector malicioso bien podría preguntar si la extranjera Agnes Heller al emigrar hacia los EE.UU. se hizo cargo de una tarea desagradable y pesada aceptando una cátedra en la New School de Nueva York. Estamos, sin embargo, acostumbrados a la discrepancia entre las teorías y las acciones de los pensadores. 
8 Imagino que Heller usa el término ético en contraposición a moral en el sentido, por así decir, post-hegeliano: los deberes éticos son los que están en vigor en una comunidad especifica, mientras que los deberes morales poseen valor universal y se aplican al nivel de la humanidad.

9 Recuerdo haber asistido en la televisión italiana a una escena grotesca y vergonzosa. En un pueblecito del sur de Italia los habitantes salieron a la calle e impidieron la llegada de un bus con veinticinco prófugos del Darfur (exclusivamente mujeres y niños). Las imágenes mostraban las caras asustadas y cansadas de los prófugos, escapados a la violencia en su país para recibir esa bella acogida, y los ciudadanos excitados gritando llenos de odio que no se los quería allí. Un pequeño detalle llamó mi atención ante esta manifestación de rechazo al Otro: las declaraciones de los habitantes a los periodistas tuvieron que ser subtituladas porque eran hechas en el dialecto estrictísimo e incomprensible de la región. Eso me suscitó el deseo de preguntar a los teóricos de la adaptación si en este caso sería más importante para los prófugos aprender el italiano o aquel dialecto tan distante (o si no sería el caso de exigir a los habitantes que se adapten a la cultura italiana dominante y dejen de hablar su dialecto).

10 Esta idea es expresada de manera eficaz por Rada Ivekovic: "La identidad del sujeto occidental se basa sobre la común pertenencia de varios individuos a un colectivo, sobre la exclusión de lo que es otro. [...] Es un fenómeno que se verifica en los momentos (históricos) de amenaza (económica o existencial o de la identidad). La nueva identidad (colectiva) se constituye a través de la negación de aquéllos que fueran empujados al margen extremo, o sea, aquéllos que no corresponden al modelo dominante prescrito" (Ivekovic 1995, 83).

11 En Slaughter 1994, 370, y en Benhabib 2002, 8. Benhabib usa el término en acepción negativa.

12 Los problemas surgen, sin embargo, cuando consideramos la posición de los individuos en el contexto de su cultura, ya que el multiculturalismo insiste principalmente sobre los derechos colectivos de los grupos culturales, derechos que pueden chocar ( $y$, de hecho, muchas veces chocan) con los derechos individuales de los miembros del grupo. Pero, lo que nos interesa en este contexto es otro aspecto.

13 Sigo aquí una intuición central freudiana y lacaniana.

14 En Taylor 2004. Taylor defiende la idea de que cada sociedad se funda en un cierto "imaginario social". Con este término él entiende "las maneras en las cuales las personas imaginan su existencia social, el modo en que ellas se acomodan con los otros, el modo en que funcionan las cosas entre ellas y sus semejantes, las expectativas que son satisfechas normalmente, y las nociones e imágenes normativas más profundas que fundamentan tales expectativas" (Taylor 2004 , 23). Este imaginario es común a los miembros de una sociedad y posibilita la existencia de prácticas comunes y de un sentido de legitimidad relativo a tales prácticas. Un imaginario social puede mudar. Nuevas prácticas pueden ser reconocidas como legitimas y hasta sustituir a las antiguas. Según Taylor esto se pasa a través de largos procesos iniciados generalmente por iniciativa de grupos minoritarios.

15 Esta actitud es caracteristica de nosotros los europeos; nadie, en países como los EE.UU. o Brasil, consideraría la busca de mejores oportunidades económicas y de vida como una razón insuficiente o incluso inaceptable (aunque esta última no sea la posición de Kristeva) para pedir acceso en esos países. Al contrario, ellos mismos se alaban por el hecho de ofrecer semejantes oportunidades a los inmigrantes que llegan allá en busca de fortuna.

16 "Preguntémonos, por ejemplo, en qué otro lugar se podria encontrar una teoría y una política más preocupadas con el respeto del otro, más vigilantes de los derechos de los ciudadanos (incluso mujeres y extranjeros, a pesar de equivocaciones y de crímenes), más preocupadas con la diversidad individual" (Kristeva 1993, 46 s). En su libro, Bonnie Honig cita el mismo pasaje (Honig 2001, 64) y llama la atención por las palabras "a pesar de equivocaciones y crimenes" que, efectivamente, parecen situar a Kristeva próxima a posiciones conservadoras e incluso reaccionarias, según las cuales los extranjeros son típicamente criminales.

17 Irónicamente, en la misma Francia cosmopolita y republicana elogiada por Kristeva, el presidente Sarkozy propuso recientemente hacer un censo con base étnica.

18 Parece que el último caso de denization ocurrió en 1873 (Berry 1944).

19 Me permito remitir a mi artículo "Democracia y exclusión. Ciudadanía y derechos políticos en la sociedad democrática" que será publicado próximamente en un libro en homenaje a Dorando Michelini.

20 La distinción entre la esfera de la política y la esfera de la moralidad o de la religión es, como es sabido, uno de los puntos más relevantes del pensamiento de Maquiavelo: en el 
ámbito de la política lo que cuenta es solamente el éxito final. Eso no significa que defienda una visión inmoral de la política, ni que cualquier resultado obtenido por el hombre político esté justificado, contrariamente a lo que piensa una interpretación vulgar de su pensamiento. La única finalidad que justifica el uso de cualquier medio es la creación de un estado estable y republicano. En tal estado, los ciudadanos deben estar dispuestos a hacer de todo para su país. Su lema bien pudiera ser una frase que Maquiavelo escribió en una carta: "Amo a mi patria más que a mi alma".

21 Hay una pluralidad de autores que se ocupan de la cuestión de las virtudes cívicas en la sociedad liberal. Entre otros, Macedo 1990, Galston 1991, Norton 1991, Dagger 1997, Kahane 1998 y Höffe 1999. Me remito también a Pinzani 2000 y 2009.

22 "No es muy probable que personas asustadas, desnacionalizadas y criminalizadas se arriesguen a ganar la visibilidad que el hecho de unirse comporta" (Honig 2001, 103).

23 De vez en cuando alguien propone incluso la creación de un banco de datos con el ADN de los ciudadanos a fin de facilitar las investigaciones criminales. Hasta ahora la cosa permaneció en el reino de la ficción política, pero sin duda habría políticos que estarian encantados con poner en marcha esta medida.

\section{BIBLIOGRAFÍA}

Alejandro, Roberto (1998): "Impossible Citizenship", en Slawner, Karen/Denham, Mark E. (eds.), Citizenship after Liberalism, Nueva York et al., Peter Lang, 9-32.
Arendt, Hannah (1987): Los orígenes del totalitarismo, Madrid, Alianza.

Bauböck, Rainer (2006): "Lealtades rivales e inclusión democrática en contextos migratorios", en Revista Internacional de Filosofía Política, n. $27,41-69$.

Behdad, Ali (2005): A Forgetful Nation: On Immigration and Cultural Identity in the United States, Durham y Londres: Duke U. P.

Benhabib, Seyla (2002): The Claims of Culture. Equality and Diversity in the Global Era, Princeton, Princeton U. P.

Berry, Edmund G. (1944): "Cives sine suffragio in England", en The Classical Journal, vol. 39, n. 8 , 490-492.

Dal Lago, Alessandro (2008): Non-Persone. L'esclusione dei migranti in una società globale, 3.a edición, Milán, Feltrinelli.

Dagger, Richard (1997): Civic Virtues. Rights, Citizenship, and Republican Liberalism, Oxford y Nueva York, Oxford U. P.

Foucault, Michel (2001): "Le jeu de Michel Foucault", en Foucault, M., Dits et écrits II, París, Gallimard, 298-329.

Galston, William (1991): Liberal Purposes. Goods, Virtues, and Diversity in the Liberal State, Cambridge, Cambridge U. P.

Hammar, Tomas (1990): Democracy and the Nation State. Aliens, Denizens, and Citizens in a World of International Migration, Aldershot, Avebury.

Heller, Agnes (1992): „Zehn Thesen zum Asylrecht", en: Die Zeit, n. ${ }^{\circ} 46$, 6.11.1992 (en: http://www.zeit. de/1992/46/Zehn-THESEN-zum-Asylrecht).

Höffe, Otfried (1999): Demokratie im Zeitalter der Globalisierung, Múnich, Beck.

Honig, Bonnie (2001): Democracy and the Foreigner, Princeton, Princeton U. P.

Ivekovic, Rada (1995): La balcanizzazione della ragione, Roma, manifestolibri.
Kahane, David J. (1998): "Liberal Virtues and Citizen Educations", en Slawner, Karen/Denham, Mark E. (eds.): Citizenship after Liberalism, Nueva York et al., Peter Lang, 103-125.

Kelsen, Hans (1975): Dottrina pura del diritto, Turín, Einaudi.

Kristeva, Julia (1993): Nations without Nationalism, Nueva York, Columbia U.P.

Lakoff, George (2008): The Political Mind: Why You Can't Understand 21st-Century American Politics with an 18thCentury Brain, Nueva York, Viking.

Macedo, Stephen (1990): Liberal Virtues. Citizenship, Virtue, and Community in Liberal Constitutionalism, Oxford, Clarendon Press.

Meyer, William J. (1998): "The Politics of Differentiated Citizenship", en Slawner, Karen; Denham, Mark E. (eds.), Citizenship after Liberalism, Nueva York et al., Peter Lang, 57-79.

Norton, David L. (1991): Democracy and Moral Development. A Politics of Virtue, University of California Press, Berkeley.

Pinzani, Alessandro (2000): "Bürgertugende und Demokratie", en Beckmann, Klaus; Mohr, Thomas e Werding, Martin (eds.). Individuum versus Kollektiv. Der Kommunitarismus als "Zauberformel"?, Nueva York et al., Peter Lang, 97-129.

Pinzani, Alessandro (2009): An den WurzeIn moderner Demokratie. Bürger und Staat in der Neuzeit, Berlín, Akademie Verlag.

Sassen, Saskia (2006): "La formación de las migraciones internacionales: implicaciones políticas", en Revista Internacional de Filosofía Política, n. ${ }^{\circ} 27$, 19-39.

Slaughter, M. M. (1994): "The Multicultural Self: Questions of Subjectivity, Questions of Power", en Rosenfeld, Michel (ed.), Constitutionalism, Identity, Difference, and Legitimacy. Theo- 
retical Perspectives, Durham, Duke U. P., 369-380.

Taylor, Charles (2004): Modern Social Imaginaries, Durham, Duke U.P.

Tully, James (1995): Strange Multiplicity. Constitutionalism in an Age of Diversity, Cambridge, Cambridge U. P. (ed.), Derechos, libertades, emancipación. Barcelona, Horsori, 127-140.

Willenbücher, Michael (2007): Das Scharnier der Macht. Der illegalisierte als homo sacer des Postfordismus, Berlín, b-books. 